\title{
Chapter 16 \\ Systems for Disaster Management in the Private Sector
}

\author{
Mashiho Suga, Kinzo Kuwana, Shingo Nagamatsu, Takahiro Nakamura, \\ and Kazuhiko Takano
}

\begin{abstract}
Disaster management is not just for the government. Various sections of the private sector carry out disaster management activities. At the time of disasters, volunteers and NPOs are well known. Corporations, on one hand, prevent accidents within and at the same time take measures to respond quickly in cases of emergency situations. The insurance system is another method of risk management that has been around since old times.
\end{abstract}

Keywords BCP · Insurance $\cdot$ Labor safety $\cdot$ Mutual aid $\cdot$ NPO $\cdot$ Volunteer

\subsection{Natural Disasters and Nonprofit Organizations}

\subsubsection{Disaster Relief and Nonprofit Organizations}

When a natural disaster that exceeds a certain level strikes, prefectures and municipalities that suffered damages set up disaster response headquarters according to local disaster management plans. The headquarters take the lead in the system for emergency response and later measure up to the point of recovery and reconstruction. In case of small disasters, the top-down organization within administration can provide effective response. The 1995 Great Hanshin Awaji earthquake in Japan, however, revealed the limits of administrative response. Large-scale disasters produce a large number of situations that require quick judgments and decisions at the same time, and administrational entities, which place priority on fairness of their response, hesitate in distributing the resources at hand until the entire picture of the damages becomes clear and the responses end up being late.

Initial fire extinguishing, grasping the damage levels and running evacuation shelters, in general, are tasks for self-support by family members or mutual support

M. Suga $(\bowtie) \cdot$ K. Kuwana $\cdot$ S. Nagamatsu $\cdot$ T. Nakamura $\cdot$ K. Takano

Faculty of Societal Safety Sciences, Kansai University, Takatsuki, Osaka, Japan

e-mail: sugam@kansai-u.ac.jp 
by residents in the areas. At the time of the Great Hanshin Awaji earthquake, however, families and residents had lost their capacities for problem-solving with declining birthrate, aging population, and urbanization, and many of the regional communities could not properly provide self- or mutual support by themselves.

What made up for these gaps of limits with public support and self-/mutual support were "goodwill citizens." Once images of devastating damages went on air, huge amounts of people, supply, and relief donations poured into the disasterstruck areas. Especially noteworthy were the "disaster volunteers" that exceeded about 1,380,000 a year (estimate by Hyogo Prefecture). They entered the disasterstruck areas and offered their labor in place for the functionally failed administrative organizations.

The regions, however, were not prepared to accept the volunteers, and a number of problems arose. This experience led to a system to have a window to accept general volunteering citizens separate from registration of skilled supporters in the disaster response system in the regional disaster management plan revised after the earthquake. Further, the volunteer center (VC), set by the Council of Social Welfare and operated through ordinary times, expanded its function to start "Disaster Relief VC" when needed to register volunteers and dispatch them to proper places.

Disaster Relief VCs turned into organizations for disaster response systems of Japan to promote "cooperative support" that compensates the limits of public support and also helps self- and mutual support. While social movements were on the rise to promote the establishment of foundations for socially contributing activities by goodwill citizens, the Act on Promotion of Specified Nonprofit Activities was enacted in March 1998, and a large number of NPOs, specialized in disaster support, were born. Earthquake volunteer activities during the Great Hanshin Awaji earthquake placed large effects on the arrangement of disaster response systems in Japan and the formations of the private nonprofit sector.

The years that followed the Great Hanshin Awaji earthquake suffered disasters at regions, and every time, "cooperative support" centered about Disaster Relief VCs made significant activities. The foundation of activities for Disaster Relief VCs gradually shaped with procurement of activity funds and management training; however, around 10 years after the earthquake, limits of the system started to emerge. Disaster Relief VC activities that dispatched large number of citizens that may lack experience or skills but were highly motivated have been highly praised. In fact, in 2004 when 10 typhoons landed on Japan, over 80 Disaster Relief VCs were set within the single year, and, at one time, 60,000 volunteers worked in disaster-struck areas. Coordinating the work of a variety of volunteers, however, that required large management work and running Disaster Relief VCs were large burdens to Council of Social Welfare offices. Another drawback was that Disaster Relief VCs had general citizens playing the central roles of activities, thus could only accept support requests possible for anyone and had to turn down requests that required special skills.

The 2011 Great East Japan earthquake caused damages over a wide area crippling the public organizations in the area, and expectations were high from the beginning for "cooperative support." The real needs, however, were more for organizations that could move large amounts of resources or specialists that could work under severe 
work conditions, rather than civilian support for individual victims. In addition, lack of resources in the disastrous areas caused difficulties in building activity centers for the volunteers and delayed the startups of Disaster Relief VCs. The needs for special skills and large resources were met by private companies, nongovernmental organizations (international NGOs), and domestic disaster-related NPOs that had accumulated experience before the earthquake disaster (Suga 2018).

Cooperative support for disaster-struck areas today is shifting toward coordinated activities through liaison meetings among NGOs, NPOs, administration, and the Council of Social Welfare. At the time of Kumamoto earthquake in 2016, the governments and private sectors provided a new form of support to the disaster areas and victim liaison meetings among a variety of organizations and entities.

\subsubsection{Disaster Recovery and Rise of Social Business}

During the Great East Japan earthquake, as we discussed in the previous section, NPOs with specialized skills came to play important roles, and a number of organizations and companies started support for disaster-struck areas in businesslike fashions. Examples of large private corporations that applied its own business strategies, as part of its corporate social responsibility (CSR) activities, to support disastrous areas include Amazon that provided relief goods using "wish lists," Honda that gave road traffic status information using its own automotive navigation system, and so on. There were a large number of other organizations and companies that posted goals to meet social needs. NPO Katariba applied its know-hows in career learning programs for high school students to start a private academy for disaster victim children in the city of Onagawa in Miyagi Prefecture. NPO Florence that provides childcare for children with illness started an indoor playing facility for children in Fukushima Prefecture. The Music Securities, Inc. applied the system of microfinance to start a service to solicit general investors to invest into disaster victim companies and collect reconstruction funds.

These business entities offer their services at cost, and they are continuing their businesses by receiving compensation from the users. Their abilities to carry on the reconstruction support activities without having to rely on grant money from the government or charity donations give them solid strength compared to other NPOs or volunteers.

The Great East Japan earthquake damaged a large number of companies mainly along the coast, and many employments were lost as well. Social business companies, like we described above, receive compensation from the users. Therefore, they are expected to offer employments in addition to providing services to support disaster victims. The METI, with the objective of reconstructing the regions from the disaster, started to support social business startups, and a large number of them started and contributed to reconstruction of the areas and employment offerings. 


\subsection{Accident Prevention Activities by Companies}

\subsubsection{Accident Prevention Activities}

Accidents and disasters that happen through corporate activities are industrial accidents if workers contract sickness, are injured, or are dead. Even if the effects of an incident are only physical, it may cause long-term influences on the surrounding areas. If an event causes harm to a third person unrelated to the corporate activities, it turns into a social issue. For this reason, whatever the industry is and in whatever form, corporations need to work on accident prevention in various forms, so they will not harm their workers with employment and also will not cause bad effects on the societies and regions around them.

Accident prevention activities with companies, in general, develop through building proper safety and health management systems, conforming to regulations about labor safety and health, and promoting voluntary activities in safety and health. The activities and methods differ with companies and job types, and further improvements are implemented to continue enhanced activities for accomplishing better accident prevention.

Educating the employees about safety knowledge is also important in accident prevention. The Industrial Safety and Health Act of Japan obligates the employer to provide safety and health education to its employees upon their employment and start of hazardous operations. The act also requests employers to make efforts in education for skill improvement and health for safety managers.

Depending on the type of work and sizes, corporations conduct a variety of accident prevention activities. In recent years, activities in accident prevention are on the table for different businesses (manufacturing, service industry, disaster recovery and reconstruction, and so on), accident types (explosion, chemical substance, heat attacks, and so on), and the actual concern (elderly worker and overwork, long working hours, and so on).

Accident prevention activities alone, of course, cannot fully stop accident breakouts. For example, the "close call reporting" that has workers' report about their own experiences tends to end up being a collection of reports of actions like "slipped" or "fell down" that the worker can recognize, and the reporting system seldom picks up cases that are hard to recognize like "misunderstanding" or "slip of memory." Only alerting the operators by writing to "be careful" in the operation manual has difficulty in its effect of preventing errors. Further, whatever the process is, new operations can expect a certain level of effect because they are new to the operators; however, as time passes, the operators get used to the operations and tend to forget cautions in the manuals (Oiri 2008). Thus, not suffering from disasters or no legal violation for now is not a good enough reason to carry on the current accident prevention activities. We should all continue aiming at further safety by identifying and organizing problems and concerns in our efforts to implement improvements. 


\subsubsection{Safety Management}

Companies with their involvement in accident prevention activities lowered the number of industrial accidents; however, the drop has leveled off since about the 1990s. Now the movement is to implement occupational safety and health management systems (OSHMS) for preventing industrial accidents and improving levels of corporate safety and health.

Discussion has been made about the reason for the leveling off of decline of industrial accidents. What were pointed out include the following: (1) Accident prevention activities are left to those in charge and post-accident measures are merely for formality, (2) retirement of baby boomers (born 1947-1949 in Japan) has made it difficult to carry on the know-how of safety in the fields, and (3) advancement in the industry diversified the risk factors that conventional measures cannot handle. When OSHMS guidelines were underway by the International Labour Office (ILO), MHLW of Japan announced Guidelines on Occupational Safety and Health Management Systems in 1999 to introduce, spread, and have companies implement OSHMS. The guideline was revised in 2006, and risk assessment, the central contents of OSHMS, has included the actual implementation of "Guidelines for Investigation of Danger and Harm, etc."

OSHMS has the following four features:

1. Company-wide promotion

Roles, responsibilities, and authorities are defined for system managers at each level (overall manager, department manager, and safety and health manager) to properly operate the system, periodically audit and review the system, and reflect opinions of workers in the operation.

2. Performing risk assessment

Investigate dangers and harm to estimate the risks. Set priorities for reducing risks, examine the risk reduction methods starting from higher priorities, and execute the measures.

3. Autonomous system based on PDCA cycle

Continue execution of the autonomous activities of (plan, do, check, act, etc.). Target improvement of safety and health standards at the workplace in a spiral manner through the checked items during system audit.

4. Procedural, written, and recorded

For clarifying "when, who, what, and how," write out safety and health guidelines, roles, responsibilities, and authorities of managers at each level, and procedures of reflecting workers' opinions, risk management, investigation of accident causes, and system audits. Also record necessary steps taken along the execution.

Introducing OSHMS was not easy in both terms of implementing a new method and coordinating it with existing measures. OSHMS are hardly in full operation, especially with small- to mid-sized companies with limited resources, and there are a number of concerns left until it is fully spread and implemented. 


\subsubsection{Labor Safety and Health}

After the industrial revolution, advancement of mechanical technologies and mass production systems led to employment of women and even children. At the time, the concept of protecting workers was weak, and a number of problems arose including long hours of labor of 12-13 h a day, poverty with low wages, a number of infections caused by these reasons, and so on. In 1833, the UK government passed the Factory Act to restrict labor by women and children. Daily work hours, however, had to wait until 1947 when a limit of $10 \mathrm{~h}$ a day was enforced.

Also in Japan, the rapid modernization and industrialization that started in the Meiji era caused serious problems of accidents and infections at factories. The social mood at the time, however, placed priority in economic growth to compete with the European and American leaders, and activities for workplace safety and accident prevention were not well accepted. On the other hand, engineers, dispatched to trips to Europe and America to learn know-how of modern industries, came back with knowledge about safety and accident prevention and tried to spread the methods in Japan. Some new leaders emerged who led efforts in assuring safety after experiencing distressful accidents that involved close people to them. The birth of modern labor regulation in Japan was its Factory Act enforced in 1916 that was over 30 years since it was first drafted. Then the Labor Standards Act was enforced in 1947 and the Industrial Safety and Health Act in 1972 for establishing the framework for protecting workers from job-related injuries, illness, and deaths.

The modern society has a big variety of industry types and job types and so are the systems for safety and health management. The business owners and workers, therefore, not only have to conform to the regulations, but it is important for them to continue efforts for improvement by building systems that suit the business operations.

\subsection{BCP and Crisis Management}

\subsubsection{Internal Control Systems for Corporations and Crisis Management}

The Great East Japan earthquake that broke out on May 11, 2011, caused enormous damages to companies. "Research on Effects of 'Great East Japan earthquake' on Publicly Listed Companies" (Tokyo Shoko Research 2011) reported that of the 1908 publicly listed companies, 652 (34.2\%) had "partial shutdown of sales or operation." Corporations have to continuously operate their businesses, and preparing crisis management against large earthquakes and accidents is indispensable for them.

Crisis management is defined: "Strategic protective actions taken within a community to prepare for, respond to, or recover from the occurrence of a crisis" (Penuel and Statler 2010). Risk management is a measures to prevent occurrence of risks, 
whereas crisis management is a concept about countermeasures after a crisis like a disaster has occurred.

A corporation prepares its crisis management system as follows: First is the setting of escalation rules. Set a rule, so when a disaster or an accident breaks out, the field quickly transfers the information to the top management. Second is the formation of a crisis response group. The top management forms emergency crisis response headquarters when it receives information about a disaster or an accident and judges if the incident is a crisis. Members and the location of the emergency response headquarters should be set beforehand and defined in the crisis management manual. Third is action plans have to be prepared. At the time of a crisis breakout, there will be confusion, and measures for the emergency crisis response headquarters to take should be defined and compiled beforehand. Fourth is the crisis simulation training. Periodically conduct simulation training with a hypothetic crisis to extract problems and to review the crisis management system.

Internal control system is a name for a combined corporate group system for risk management, crisis management, and compliance. The Companies Act enacted in 2005 obligated business owners to construct internal control systems. The Financial Instrument and Exchange Act enacted in 2006 enforced internal control reporting to publicly listed companies. The two acts urge business owners to organize crisis management systems, and they affected the spread of guidelines by the government as we will discuss later.

\subsubsection{Crisis Management and BCP}

Business continuity planning (BCP) is defined as "Plans identifying all the process and actions necessary to permit an organization to perform its crucial functions and activities during and after a disaster" (Penuel and Statler 2010). In other words, BCP is plans to prepare during regular times, about how to continue or quickly recover from a major disaster or accident that is a predictable risk that stops the business.

An actual BCP is prepared in the following manner: First is risk analysis. Identify risk events that will stop the business, and determine the worst scenario for the corporate group. Second is to set the basic guideline and identify the important businesses, that is, to identify the business important for the business group and ones that are demanded socially. Third is to set the recovery target. Once important businesses are identified, set the time to recover them from the outbreak. And fourth is to set the plans for restarting the business. Identify necessary resources for the restart, and build plans for the business restart. Once the four steps are complete, periodically carry out crisis simulation training to identify problems by reviewing the BCP.

Recovery from disasters are said to be the origin of BCP. Recovery from disasters is a concept started primarily in the USA in the 1950s when companies stored backup documents and electronic data on alternate sites. When the simultaneous terror attack took place on September 11, 2001, in the USA, financial institutions 
moved to their alternate offices to continue trading, and their minimizing of the loss from business interruption caught the eyes of the world. This incident caused the spread of BCP as total plans for business continuation.

Later in the USA, after the devastation by hurricane Katrina, "Implementing Recommendations of the 9/11 Commission Act of 2007" (Public Law 110-53 2011) was approved in the Congress in August of 2007. Based on Title IX "Private Sector Preparedness" of this act, the "voluntary private sector preparedness accreditation and certification program" was established with the Department of Homeland Security being the primary government department. The program encourages private businesses to establish voluntary disaster measures with the government setting the certification standards.

\subsubsection{BCPs in Japan and Their Future}

Companies in Japan have been hit by a number of crises in the past. They were the 1995 Great Hanshin Awaji earthquake, the 2003 spread of SARS that started from Guangdong in China, the 2007 Chuetsu offshore earthquake, the 2008 outbreak of avian influenza (H5N1), and so on. Ministries and agencies in Japan have shown the guideline and encouraged companies to set their BCPs and start applying them. Guidelines for natural disasters like earthquakes have been published by the Central Disaster Prevention Council of the Cabinet Office in 2005 (first edition) and 2009 (second edition). An English version of "Business Continuity Guidelines - Strategies and Responses for Surviving Critical Incidents - Third Edition" (Cabinet Office 2013) is now available. For infectious pandemics, MHLW has published "Guideline for Pandemic Influenza Preparedness at Business Entities and Establishments" in 2007 and for interruption of information communication. The METI published "Guidelines on Formulating and Implementing BCPs" in 2005 as an appendix to "Report: Information Security Governance at Corporations." For smallto mid-sized corporations, the Small and Medium Enterprise Agency published "Guidelines on Formulating and Implementing BCPs for Small and Medium Enterprises (METI 2005)."

Large corporations in Japan are carrying out leading efforts in implementing BCPs. According to "Survey of Corporate Implementation of Measures for Business Continuity and Disaster Prevention in 2015" (2016) by the Cabinet Office, $60.4 \%$ of large corporations answered they have set their BCP plans, whereas only $29.9 \%$ of small- to mid-sized companies responded they have. Reasons for BCP plans not spreading into small- to mid-sized companies are their lack of resources to spare in preparing against natural disasters and probably the business owners' low level of consciousness about disaster prevention. 


\subsection{Market Economy-Based Disaster Management Activities}

\subsubsection{Insurance System}

\subsubsection{History of Insurance Systems and Their Structure}

There are two roots for what is called insurance today. One root is the maritime insurance that started in Italy in the fourteenth century when trading in the Mediterranean developed. This type has now developed into property and casualty insurance and life insurance. Those that offered this type of insurance organized what are insurance companies now. They are businesses of insurance. The other root is mutual aid against fires that started in the fifteenth-century Germany. They are now called mutual aid or social insurance. The insurance is mutual aid among the policy holders.

The insurance premium for the entire world in 2015 was JPY 304 trillion (about US\$ 3 trillion) and JPY 242 trillion (about US\$ 2 trillion), and their sum of JPY 546 trillion (about US\$ 5 trillion) is greater than the Japanese GDP of JPY 532 trillion (about US\$ 5 trillion) and was equivalent to $6.23 \%$ of the entire world GDP (Swiss Re 2016). These figures include premiums for mutual aids.

Life insurance makes payment upon death or survival of a person and property and casualty insurance upon occurrence of damage. Thus, there are a number of property and casualty insurance policies for various risks in the market. Property and casualty insurance may cover airplane accidents or large-scale plant accidents when a single accident causes a huge insurance payment with a single policy. It may also have to face huge payments upon a large natural disaster like an earthquake or typhoon for making multiple insurance payments at the same time. In other words, there is a possibility that a single insurance company cannot cover the huge insurance payment. To cope with such situations, insurance companies over the world are policyholders of reinsurance, i.e., insurance of insurance, to share risks of such cases. Such reinsurance has been around for many years. The oldest of such reinsurance contract on records is one about a cargo on a ship in 1370 (Carter 1983). Hearings with reinsurance companies, Munich Re, Swiss Re, and Lloyds, revealed that insurance companies in Japan also entered reinsurance contracts with overseas reinsurance companies since the late nineteenth century. Currently, there are 41 life insurance companies and 52 property and casualty insurance companies with licenses to operate in Japan (GIAJ 2017; LIAJ 2017).

\subsubsection{Disaster Management Functions with Insurances}

Many of us think that the function of an insurance is to make insurance payments upon outbreak of accidents, i.e., functions to recover the original state. Premium for insurance policyholders that engage in activities with large risks are naturally high. 
Making use of this fact, policies over the world are leading to disaster reduction with increase in compulsory insurance premium for conducting activities that may cause damage to social properties. Forcing insurance to the business owner leads to assuring saving of the victims as well in case a damage breaks out. Also, for example, worker's compensation to cover the responsibility of business owners stated in the Labor Standards Act of Japan has its premium affected by history of accidents with the business. This policy leads to efforts by business entities to reduce work-related accidents. The total amount of worker's compensation paid in 2015 in Japan amounted to JPY 792.1 billion (about US\$ 7.2 billion) (MHLW 2017).

On a separate issue, automobile liability insurance, a compulsory insurance for automobile drivers, made insurance payment of JPY 792.1 billion (about US\$ 7.2 billion) in fiscal year (starting in April) 2015 (GIAJ 2017). The amount of voluntary insurance payment made for automobile caused personal injuries and property damages amounted JPY 163.7 billion (about US $\$ 1.5$ billion) in the same fiscal year (GIROJ 2017). These insurance payments are made for the damages to the victims caused by the policyholders that caused the accidents. Without these insurances, the victims have to receive liability payments from the driver through private settlements or litigations causing high costs to the victims to receive relief. Insurance is something we cannot live without.

Furthermore, disaster management measures are subject to reviews by those investing into overseas reinsurance companies. Measures that seem questionable to the reviews would raise the premium payment for the reinsurance that covered the measures. An increase in the reinsurance premium results in an increase in the insurance premium in Japan, and the monetary incentive would correct the disaster management measures that looked questionable to the eyes of the reinsurance company investors.

\subsubsection{Disaster Management Activities by Other Private Sectors}

\subsubsection{History of Disaster Management Activities by Other Private Sectors}

The private sectors besides insurance companies involved with disaster management are insurance brokers, insurance agents, and risk-consulting companies affiliated with insurance companies. Insurance brokers, independently from insurance companies, have been providing advices for long years to the policyholders about disaster management. One of the broker company giants Marsh \& McLennan Companies has been around since the mid-nineteenth century. Other than insurance brokers are risk-consulting companies affiliated to general construction companies or banks. New venture businesses in risk-consulting with no affiliation to insurance companies, general constructors, or banks are starting to come to existence. 


\subsubsection{Outline of Disaster Management Activities by Other Private Sectors}

Giant insurance brokers today analyze damages from natural disasters with simulation models and issue risk-linked securities. The annual sales in fiscal year 2015 for the publicly listed five major insurance brokers (Marsh \& McLennan, Aon, Arthur J. Gallagher \& Co., Willis Tower Watson, Brown \& Brown Insurance) summed to about JPY 4250 billion (about US $\$ 39$ billion). Note that insurance brokers make their profits primarily from commission for insurance sales; thus, sales from disaster management activities make part of the JPY 4250 billion sales. Risk-consulting companies related to large corporations have been involved in consulting for disaster management activities for large private companies. On the other hand, riskconsulting ventures offer more elaborate services with adjustments based on customer locations. In any case, consulting by these private sectors will allow various users to effectively carry out disaster management activities.

\section{References}

Cabinet Office. (2013). Business continuity guidelines - Strategies and responses for surviving critical incidents - Third edition. http://www.bousai.go.jp/kyoiku/kigyou/pdf/guideline03_en. pdf. Accessed 3 June 2018.

Cabinet Office. (2016). Survey of corporate implementation of measures for business continuity and disaster prevention in 2015. http://www.bousai.go.jp/kyoiku/kigyou/pdf/h27_bcp_report.pdf. Accessed 1 June 2018.

Companies Act. (2005). http://www.japaneselawtranslation.go.jp/law/detail/?id=2035\&vm=04\& re $=02$. Accessed 2 July 2018.

Carter, R. L. (Ed.). (1983). Reinsurance. Dordrecht: Springer.

Factory Act. (1833). An act to regulate the labour of children and young persons in the mills and factories of the United Kingdom 29 August 1833. In Anno Tertio \& Quarto Gulielmi IV Regis. Cap CIII, London.

GIAJ. (2017). Fact book 2016-2017. The General Insurance Association of Japan.

GIROJ. (2017). Automobile insurance in Japan 2017. General Insurance Rating Organization of Japan. https://www.giroj.or.jp/english/press_2017/20170906.html (in English). Detailed information is found at https://www.giroj.or.jp/. (in Japanese) Accessed 4 July 2018.

Industrial Safety and Health Act. (1972). Act No. 57. http://www.japaneselawtranslation.go.jp/law/ detail_main?re=\&vm=\&id=1926. Accessed 1 July 2018.

Labor Standards Act. (1947). Act No. 49, Amendment Act No. 42 (2012). http://www.jil.go.jp/ english/laws/documents/l.standards2012.pdf. Accessed 1 July 2018.

LIAJ. (2017). Life insurance fact book. The Life Insurance Association of Japan.

METI. (2005). Guidelines on formulating and implementing BCPs (in Japanese). http://www.meti. go.jp/policy/netsecurity/docs/secgov/2005_JigyoKeizokuKeikakuSakuteiGuideline.pdf. Accessed 1 June 2018.

METI. (2006). Guidelines on formulating and implementing BCPs for small and medium enterprises. http://www.chusho.meti.go.jp/keiei/antei/download/110728JapanBCP_SME_Eng.pdf. Accessed 6 June 2018. 
MHLW. (2007). Guideline for pandemic influenza preparedness at business entities and establishments. Pandemic Influenza Experts Advisory Committee, Ministry of Health, Labor and Welfare. http://www.mhlw.go.jp/bunya/kenkou/kekkaku-kansenshou04/pdf/09-e11.pdf. Accessed 1 June 2018.

MHLW. (2017). Heisei 27 nendo Rodosha Saigai Hosho Hoken Jigyo Nenpo [Annual report of worker's compensation business in fiscal year 2015]. Ministry of Health, Labor and Welfare (in Japanese). http://www.mhlw.go.jp/toukei/itiran/roudou/hoken-jigyo/gaiyou/h27_nenpou. html. Access 4 July 2018.

Oiri, M. (2008). Sangyo Jiko - Haikei to Taisaku [Industrial accidents - Their background and countermeasures]. In M. Mukai, \& K. Renge (Eds.), Gendai Shakai no Sangyo Shinrigaku [Industrial psychology in the modern society] (pp. 126-147). Tokyo: Fukumura Publishing.

Penuel, K. B., \& Statler, M. (Eds.). (2010). Encyclopedia of disaster relief (Vol. 1). London: SAGE. Public Law 110-53. (2011). Implementing recommendations of the 9/11 Commission Act of 2007, 110th congress, U.S. Government Printing Office, Washington D.C. https://www.congress.gov/ 110/plaws/publ53/PLAW-110publ53.pdf. Accessed 6 June 2018.

Suga, M. (2018). Problems with "disaster relief volunteers". In Faculty of societal safety science, Kansai University (Ed.), The Fukushima and Tohoku disaster - A review of the five-year reconstruction effort (pp. 195-216). Amsterdam: Elsevier.

Swiss Re, Sigma No. 3, World Insurance in 2015, Swiss Re Ltd, Zürich.

\section{Major Insurance Brokers}

Aon: http://aon.com/

Arthur J. Gallagher \& Co.: http://www.ajg.com/

Brown \& Brown Insurance : http://www.bbinsurance.com/

Marsh \& McLennan: http://www.mmc.com/

Willis Tower Watson: http://www.willis.com/

Open Access This chapter is licensed under the terms of the Creative Commons AttributionNonCommercial-NoDerivatives 4.0 International License (http://creativecommons.org/licenses/bync-nd/4.0/), which permits any noncommercial use, sharing, distribution and reproduction in any medium or format, as long as you give appropriate credit to the original author(s) and the source, provide a link to the Creative Commons license and indicate if you modified the licensed material. You do not have permission under this license to share adapted material derived from this chapter or parts of it.

The images or other third party material in this chapter are included in the chapter's Creative Commons license, unless indicated otherwise in a credit line to the material. If material is not included in the chapter's Creative Commons license and your intended use is not permitted by statutory regulation or exceeds the permitted use, you will need to obtain permission directly from the copyright holder. 